\title{
CRESCIMENTO IN VITRO DE DENDROBIUM PHALAENOPSIS C.V. "MADAME POMPADOUR" CULTIVADAS EM DIFERENTES MEIOS DE CULTURA E NÍVEIS DE PH
}

\author{
Luana Oliveira Gonçalves Santos* \\ Patrícia Franco Gianini** \\ Cristiano Pedroso-de-Moraes ${ }^{* * *}$
}

RESUMO: Orquídeas possuem um desenvolvimento vegetativo lento e necessidades específicas, fato que eleva o seu custo de produção e torna indispensável o desenvolvimento de técnicas alternativas de reprodução, como a semeadura in vitro. O presente trabalho teve por objetivo avaliar o crescimento in vitro de Dendrobium phalaenopsis "Madame Pompadour" no meio de cultivo 1/2MS e em dois meios a base dos fertilizantes comerciais Hyponex ${ }^{\circledR}$ (NPK 6,5-6-19) e Kristalon Laranja ${ }^{\circledR}$ (NPK 6-12-36), submetidos a três níveis de pH (5,3, 5,8 e 6,3). Para tanto, sementes foram distribuídas em quatro frascos de cada meio e, após 180 dias de cultivo, foram retiradas aleatoriamente vinte plântulas de cada frasco para avaliação das variáveis: altura das plântulas, comprimento da maior raiz, comprimento da maior folha, número de raízes, massas das matérias fresca e seca. Os dados obtidos foram submetidos à ANOVA e ao teste de Tukey a 5\%. O meio de cultura mais eficiente no crescimento de plântulas de Dendrobium phalaenopsis "Madame Pompadour" foi o meio Kristalon Laranja ${ }^{\circledR}$ com nível de pH de 6,3 que apresentou as maiores médias para todas as variáveis analisadas.

PALAVRAS-CHAVE: Denphal; Orchidaceae; Propagação.

\section{IN VITRO GROWTH OF DENDROBIUM PHALAENOPSIS C.V. "MADAME POMPADOUR" CULTIVATED IN DIFFERENT MEDIA AND PH LEVELS}

ABSTRACT: Since orchids have a slow vegetal development and specific needs, their production costs are high and the development of alternative techniques for

Curso de Especialização em Biotecnologia Centro Universitário Herminio Ometto de Araras (UNIARARAS), Brasil.

** Responsável Técnica pela Disciplina de Biotecnologia Vegetal do curso de Especialização em Biotecnologia Centro Universitário Herminio Ometto de Araras (UNIARARAS), Brasil.

*** Dr. Biologia Vegetal; Docente de Biotecnologia Vegetal e Produção Vegetal do Curso de Especialização em Biotecnologia Centro Universitário Herminio Ometto de Araras (UNIARARAS), Brasil.

E-mail de correspondência: pedroso@uniararas.br 
reproduction, such as in vitro seeding, are required. Current study assesses the in vitro growth of Dendrobium phalaenopsis, a.k.a. "Madame pompadour", in culture medium $1 / 2 \mathrm{~ms}$ and two media based on commercial fertilizers hyponex ${ }^{\circledR}$ (NPK 6.5-6-19) and Kristalon Orange ${ }^{\circledR}$ (NPK 6-12-36), at three pH levels (5.3, 5.8 and 6.3). Seeds were placed in four flasks with each medium and 20 seedlings were removed randomly after 180 days of culture from each flask to evaluate the following variables: plant height, length of the greatest root, length of the greatest leaf, number of roots, fresh and dry matter mass. Data were submitted to two-way ANOVA and Tukey's test at 5\%. The most efficient culture medium in the growth of Dendrobium phalaenopsis seedlings was kristalon orange ${ }^{\circledR}$ with $\mathrm{pH} 6.3$ with the highest medium rates for all variables analyzed.

KEY WORDS: Denphal; Orchidaceae; Propagation.

\section{INTRODUÇÃO}

Orquídeas são plantas ornamentais muito procuradas e de elevado valor comercial (TRUJILLO; HERNANDEZ, 1999). Sua presença é marcante na floricultura, sendo utilizadas tanto como flores de corte, na composição de arranjos florais e buquês de noivas, como plantas de vaso, com a longevidade mantida por várias semanas (LORENZI; SOUZA, 1999; PEDROSO-DE-MORAES et al., 2007a; PEDROSODE-MORAES et al., 2007b).

Na família, o gênero Dendrobium compreende cerca de 1500 espécies e, atualmente, é considerado o mais produzido e comercializado, tanto no Brasil quanto no exterior (PEDROSO-DE-MORAES et al., 2007a).

Originárias da China e do Himalaia, as plantas desse gênero necessitam de local ventilado, temperatura de $15-25^{\circ} \mathrm{C}$, regas regulares na primavera e no verão e mais espaçadas no outono e inverno (SCHELPE; STEWART, 1990; LORENZI; SOUZA, 1999; PEDROSO-DE-MORAES et al., 2011). As espécies que compõem esse gênero são consideradas plantas epífitas ou litófitas (SCHELPE; STEWART, 1990) e a grande maioria delas floresce no final do inverno ao início da primavera (PEDROSO-DEMORAES et al., 2007b; PEDROSO-DE-MORAES et al., 2011).

Hibridações no gênero Dendrobium visam à produção de cultivares de interesse comercial (PRAKASH; GOH, 1996), ou seja, são realizadas para propiciar 
floração precoce, estender a época de floração, expandir o número de flores, obtenção de novos padrões de cores e formas (DAVIDSON, 1994) e de espécimes mais vigorosos, capazes de sobreviver a intensas variações ambientais (PIMENTA, 2006; PEDROSO-DE-MORAES et al., 2007b). Para a propagação em larga escala de cultivares obtidas por meio de hibridação no gênero, como tentativa de se minimizar o tempo de obtenção de mudas, é comum no melhoramento genético a autofecundação artificial entre plantas selecionadas (KERBAUY, 1995).

Uma das cultivares de maior expressão comercial do gênero é Dendrobium phalaenopsis c.v. "Madame Pompadour", que apresenta flores rosas-escuras de tamanho médio, pétalas planificado-arredondadas, labelo encompridado de ápice arredondado com mácula roxo-escura na base, pseudobulbos vigorosos e folhas verde-escuras. Por suas características epifíticas, necessita principalmente de elevada umidade, luminosidade e excelente drenagem ao redor das raízes para um bom desenvolvimento em viveiro (SCHELPE; STEWART, 1990).

Para a propagação e produção de orquídeas em larga escala, além da seleção de genótipos, é fundamental o estabelecimento e adequação de meios de cultivo para a germinação e crescimento em condições laboratoriais (ARDITTI; ERNEST, 1992; KERBAUY, 1995; KAMEMOTO et al., 1999). Sendo que diversos trabalhos sobre a germinação in vitro de espécies do gênero são conflitantes em relação ao meio de cultivo utilizado, fonte de carbono e pH (PEDROSO-DE-MORAES et al., 2000; PEDROSO-DE-MORAES et al., 2007b).

Assim, o presente trabalho teve por objetivo avaliar o crescimento in vitro de Den. phalaenopsis c.v. "Madame Pompadour" cultivadas em diferentes meio de cultura e níveis de $\mathrm{pH}$.

\section{MATERIAL E MÉTODOS}

Para a realização do trabalho, cinco flores de plantas diferentes (PEDROSODE-MORAES et al., 2009a; PEDROSO-DE-MORAES et al., 2009b; CORDEIRO et al., 2011; CUNHA et al., 2011; DEZAN et al., 2012) da espécie Dendrobium phalaenopsis c.v. "Madame Pompadour" foram autopolinizadas artificialmente em setembro de 
2013, no viveiro de mudas do Centro Universitário Hermínio Ometto - Uniararas, Araras (SP). Seis meses após a autopolinização foram coletadas sementes dos frutos maduros, as quais foram levadas ao Laboratório de Botânica e Análises Ambientais institucional para o início do cultivo in vitro.

$\mathrm{O}$ experimento foi realizado em delineamento experimental $3 \times 3$ (meio $\mathrm{x}$ $\mathrm{pH})$ em delineamento experimental inteiramente casualizado.

Foram preparados três tipos de meios de cultura, sendo o primeiro composto por meio de cultivo MS (MURASHIGE; SKOOG, 1962) com metade da concentração de macronutrientes (controle), e dois por meios compostos pelos fertilizantes Hyponex $^{\circledR}$ (NPK 6,5-6-19) e Kristalon Laranja ${ }^{\circledR}$ (NPK 6-12-36) a 2 g L$^{-1}$. Nos meios a base de fertilizantes, não houve quaisquer acréscimos de micronutrientes. Todos os meios de cultivo foram acrescidos de $1 \mathrm{~g} \mathrm{~L}^{-1}$ de carvão ativado, $30 \mathrm{~g} \mathrm{~L}^{-1}$ de sacarose $\mathrm{e}$ tiveram seus pH ajustados para 5,3, 5,8 e 6,3 antes da adição de $7 \mathrm{~g} \mathrm{~L}^{-1}$ de ágar. Logo após, $50 \mathrm{~mL}$ de cada meio foram vertidos em quatro frascos de $250 \mathrm{~mL}$ e esterilizados em autoclave a $121{ }^{\circ} \mathrm{C}$ e $1 \mathrm{~atm}$ de pressão durante 20 minutos (ARDITTI; ERNEST, 1992).

As sementes foram desinfestadas por imersão em hipoclorito de sódio a 5\%, sendo submetidas à agitação na solução durante cinco minutos, em tubos Eppendorf $^{\circledR}$ (PEDROSO-DE-MORAES et al., 2009a; PEDROSO-DE-MORAES et al., 2009b). Posteriormente, os tubos foram mergulhados em álcool 70\% e levados à câmara de fluxo laminar, onde as sementes foram lavadas quatro vezes em água destilada com o auxílio de seringa de $1 \mathrm{~mL}$. Ainda utilizando-se da seringa, as sementes juntamente com $1 \mathrm{~mL}$ de água destilada foram depositadas nos frascos contendo os meios de cultura (ARDITTI; ERNEST, 1992).

Foram semeados quatro frascos por tratamento sendo inoculadas, por recipiente, $1 \mathrm{~g}$ de sementes. Os frascos semeados foram fechados com tampa plástica transparente e mantidos durante 180 dias em câmara climática (B. O. D. MA 403), à temperatura de $25 \pm 2{ }^{\circ} \mathrm{C}$, sob fotoperíodo de 12 horas de luz com intensidade luminosa de aproximadamente $40 \mu \mathrm{mol} \mathrm{m}^{-2} \mathrm{~s}^{-1}$ (PEDROSO-DE-MORAES et al., 2009a; PEDROSO-DE-MORAES et al., 2009b).

Para análise estatística, foram utilizados vinte indivíduos de cada frasco, retirados aleatoriamente dos meios de cultura (PEDROSO-DE-MORAES et al., 2009b; CUNHA et al., 2011). 
Ao final do trabalho foi avaliada a altura das plântulas (AP), comprimento da maior raiz (CMR), comprimento da maior folha (CMF), número de raízes (NR), massa da matéria fresca (MMF) e massa da matéria seca de plântulas (PMS) (CUNHA et al., 2011).

Os dados foram submetidos à análise de variância e a médias comparadas pelo teste de Tukey a $5 \%$ de probabilidade. Para as avaliações, os dados foram transformados em $\operatorname{arcsen} \sqrt{(X+0,5)}$ visando à estabilização da variância e favorecimento da homogeneidade das amostras (SANTANA; RANAL, 2004).

\section{RESULTADOS E DISCUSSÃO}

Os resultados demonstraram que as plântulas de Dendrobium phalaenopsis c.v. "Madame Pompadour", cultivadas em meio de cultura Kristalon Laranja ${ }^{\circledR}$ e pH 6,3 , apresentaram as maiores médias para todas as variáveis analisadas quando comparadas aos outros meios de cultivo associados aos demais níveis de $\mathrm{pH}$ (Tabela 1). O meio de cultivo $1 / 2 \mathrm{MS}$ com nível de $\mathrm{pH}$ ajustado para 5,3 foi o que obteve as menores médias dentre as interações analisadas estatisticamente.

O desenvolvimento de sementes de orquídeas in vitro varia de acordo com a cultivar, o meio de cultivo utilizado e o $\mathrm{pH}$ ideal para a espécie reproduzida. Sob tal ótica, para um desenvolvimento adequado das orquídeas, objetivando redução de custos e alta produtividade, faz-se necessária a combinação ótima entre tais fatores, definindo assim a tecnologia empregada no cultivo in vitro (STANCATO et al., 2001).

A maior parte das espécies de orquídeas germinam bem em pHs entre 4,8 e 5,2, com amplitude entre os pHs 3,6 e 7,6 (ARDITTI; ERNST, 1984). Entretanto, para um crescimento adequado da maioria das espécies de orquídeas, a faixa que revela o melhor desenvolvimento de plântulas é a de 5,0 a 6,5 (PIERIK, 1987; KÄMPF, 2000), o que corrobora com o fato de que orquidicultores especializados em orquídeas do gênero Dendrobium ajustam seus níveis de $\mathrm{pH}$ para 6,0, enquanto os produtores de diversos gêneros utilizam o nível de $\mathrm{pH}$ 5,8 em suas biofábricas como forma de facilitar a produção in vitro de orquídeas em geral (PEDROSO-DE-MORAES, 2000). Contudo, pHs entre 5,8 e 6,0 apresentam os melhores resultados culturais para os 
representantes da família, sejam eles terrestres, litófitos ou epífitos (CHIU et al., 2011; CUNHA et al., 2011; KEEL et al., 2011; LIAO et al., 2011; ROY et al., 2011).

Mesmo com a discordância entre as faixas de $\mathrm{pH}$ ideal entre autores, existe consenso no fato de que substratos levemente ácidos favorecem o desenvolvimento de orquídeas (ARDITTI, 1977). Porém, vale ressaltar que pHs mais ácidos, ou seja, abaixo de 5,0, geram deficiências nutricionais relacionadas à incorporação de nitrogênio, potássio, cálcio, magnésio e boro (KÄMPF, 2000).

Tabela 1. Médias obtidas para as variáveis: número de raízes (NR), altura das plântulas (AP), comprimento da maior raiz (CMR), comprimento da maior folha (CMF), massa da matéria fresca (PMF) e massa da matéria seca (PMS), de plântulas de Dendrobium phalaenopsis "Madame Pompadour", cultivadas em três diferentes meio de cultura e níveis de $\mathrm{pH}$. CV(\%) $=$ Coeficiente de variação

(continua)

\begin{tabular}{|c|c|c|c|c|c|c|}
\hline \multirow{3}{*}{ Meio de cultivo } & \multicolumn{6}{|c|}{$\mathrm{pH}$} \\
\hline & 5,3 & 5,8 & 6,3 & 5,3 & 5,8 & 6,3 \\
\hline & \multicolumn{3}{|c|}{ NR } & \multicolumn{3}{|c|}{$\mathrm{AP}(\mathrm{cm})$} \\
\hline $\begin{array}{c}\text { MS } 1 / 2 \text { macro } \\
\text { nutrientes }\end{array}$ & $1,11 \mathrm{Ac}$ & $1,31 \mathrm{Bb}$ & $1,98 \mathrm{Ba}$ & $1,02 \mathrm{Cc}$ & $1,26 \mathrm{Cb}$ & $1,45 \mathrm{Ca}$ \\
\hline Hyponex & $1,12 \mathrm{Ac}$ & $1,32 \mathrm{Bb}$ & $1,81 \mathrm{Ca}$ & $1,14 \mathrm{Bc}$ & $1,45 \mathrm{Bb}$ & $2,03 \mathrm{Ba}$ \\
\hline Kristalon & $1,14 \mathrm{Ac}$ & $1,69 \mathrm{Ab}$ & $2,21 \mathrm{Aa}$ & $1,39 \mathrm{Ac}$ & $1,72 \mathrm{Ab}$ & $2,68 \mathrm{Aa}$ \\
\hline $\mathrm{F} \cdot \mathbf{M c}$ & \multicolumn{3}{|c|}{$17,1^{*}$} & \multicolumn{3}{|c|}{$17,3^{*}$} \\
\hline $\mathrm{F}-\mathrm{pH}$ & \multicolumn{3}{|c|}{$12,7 * *$} & \multicolumn{3}{|c|}{$8,1^{* *}$} \\
\hline F - Mc x pH & \multicolumn{3}{|c|}{$13,9 * *$} & \multicolumn{3}{|c|}{$8,7^{* *}$} \\
\hline $\mathrm{CV}(\%)$ & \multicolumn{3}{|c|}{4,8} & \multicolumn{3}{|c|}{9,4} \\
\hline & \multicolumn{3}{|c|}{ CMR (cm) } & \multicolumn{3}{|c|}{ CMF (cm) } \\
\hline $\begin{array}{c}\text { MS } 1 / 2 \text { macro } \\
\text { nutrientes }\end{array}$ & $0,61 \mathrm{Cc}$ & $0,71 \mathrm{Cb}$ & $1,03 \mathrm{Ca}$ & $1,09 \mathrm{Bc}$ & $1,17 \mathrm{Bb}$ & $1,25 \mathrm{Ca}$ \\
\hline Hyponex & $0,73 \mathrm{Bc}$ & $0,94 \mathrm{Bb}$ & $1,14 \mathrm{Ba}$ & $1,08 \mathrm{Bc}$ & $1,20 \mathrm{Bb}$ & $1,44 \mathrm{Ba}$ \\
\hline Kristalon & $0,92 \mathrm{Ac}$ & $1,16 \mathrm{Ab}$ & $1,32 \mathrm{Aa}$ & $1,53 \mathrm{Ac}$ & $1,68 \mathrm{Ab}$ & $1,82 \mathrm{Aa}$ \\
\hline F - Mc & \multicolumn{3}{|c|}{$4,2 * *$} & \multicolumn{3}{|c|}{$9,9 * *$} \\
\hline $\mathrm{F} \cdot \mathrm{pH}$ & \multicolumn{3}{|c|}{$4,5 * *$} & \multicolumn{3}{|c|}{$6,4^{* *}$} \\
\hline F - Mc x pH & \multicolumn{3}{|c|}{$2,5^{*}$} & \multicolumn{3}{|c|}{$11,3^{*}$} \\
\hline CV(\%) & \multicolumn{3}{|c|}{6,48} & \multicolumn{3}{|c|}{13,24} \\
\hline & \multicolumn{3}{|c|}{ PMF (g) } & \multicolumn{3}{|c|}{ PMS (g) } \\
\hline
\end{tabular}


(conclusão)

\begin{tabular}{|c|c|c|c|c|c|c|}
\hline \multirow{3}{*}{ Meio de cultivo } & \multicolumn{6}{|c|}{ pH } \\
\hline & 5,3 & 5,8 & 6,3 & 5,3 & 5,8 & 6,3 \\
\hline & \multicolumn{3}{|c|}{ NR } & \multicolumn{3}{|c|}{$\mathrm{AP}(\mathrm{cm})$} \\
\hline Kristalon & $0,17 \mathrm{Ac}$ & $0,42 \mathrm{Bb}$ & $0,54 \mathrm{Aa}$ & $0,6 \mathrm{Ab}$ & $0,6 \mathrm{Ab}$ & $0,9 \mathrm{Aa}$ \\
\hline F - Mc & & $5,8^{* *}$ & & & $17,1^{*}$ & \\
\hline $\mathrm{F} \cdot \mathrm{pH}$ & & $2,5^{* * *}$ & & & $19,3^{*}$ & \\
\hline$F-M c \times p H$ & & $1,9^{*}$ & & & $16,8^{*}$ & \\
\hline CV(\%) & & 13,76 & & & 17,9 & \\
\hline
\end{tabular}

Médias seguidas por letras iguais não diferem entre si pelo teste de Tukey a $5 \%$ de probabilidade. Letras maiúsculas representam análise nas colunas e minúsculas nas linhas. * significativo à $p<0,05$; ** significativo à $p<0,01 ;$ ns = não significativo.

Com relação aos meios de cultivo, os resultados analisados (Tabela 1) se apresentam de acordo com os obtidos para as espécies de orquídea Cattleya loddigesii (PEDROSO-DE-MORAES et al., 2009a), C. tigrina (PEDROSO-DE-MORAES et al., 2009b), C. amethystoglossa $x$ (C. dupreana $x$ Laelia purpurata) (CORDEIRO et al., 2011), Brassavola perrinii x C. loddigesii (CHIAPIM et al., 2013) e para Artemisia absintbium (Asteraceae) (CAVALINI et al., 2014), para as quais houve incremento nas médias obtidas para as variáveis fitotécnicas: altura das plântulas (AP), matéria fresca (MF), matéria seca (MS), comprimento da maior raiz (CMR) e comprimento da maior folha (CMF), sob mesmas condições experimentais nas quais foi desenvolvida a presente investigação.

Resultados intermediários para as variáveis fitotécnicas avaliadas foram obtidos pelo uso do meio de cultivo de MS (Tabela 1). Mesmo o meio MS tendo sido desenvolvido inicialmente para o uso em cultivo de tecido de tabaco (MURASHIGE; SKOOG, 1962), o mesmo demonstra-se efetivo como substrato nutritivo para muitas espécies de orquídeas (MASSARO et al., 2012). Este apresenta altos níveis de nitrogênio e potássio em concentrações superiores a de outros meios utilizados, além de ser o único a possuir nitrogênio em forma de nitrato de amônio (RODRÍGUEZ et al., 2005). Contudo, caracteriza meio de cultivo mais dispendioso para o produtor (PEDROSO-DE-MORAES, 2000).

As avaliações realizadas em dois meios de cultivo MS (MURASHIGE; SKOOG, 1962), KC (KNUDSON, 1946), RL (ROSA; LANERI, 1977) e VW (VACIN; WENT, 1949), 
para germinação e desenvolvimento de plântulas de Den. cripidatum, evidenciaram diferentemente do obtido neste trabalho, que o meio nutritivo MS apresentou os melhores resultados para desenvolvimento vegetativo da espécie (REDDY et al., 1992).

Para L. cinnabarina em trabalho desenvolvido com diferentes composições de meio de cultura e para Schomburgkia gloriosa em meio MS composto por metade da concentração de macro nutrientes e, em meios à base dos fertilizantes Hyponex ${ }^{\circledR}$ e Kristalon Laranja ${ }^{\circledR}$, foram obtidos bons resultados no cultivo in vitro em meio MS 1 1/2 macro nutrientes (STANCATO; FARIA, 1996; DEZAN et al., 2012).

Para Catasetum fimbriatum também foi verificado maiores índices de massa fresca, massa seca e comprimento de plântulas pela utilização de meio de cultura MS $1 / 2$ macro nutrientes em comparação aos meios à base de fertilizantes NPK (REGOOLIVEIRA; FARIA, 2005). Em Oncidium baueri as análises biométricas relativas à altura da parte aérea indicaram melhores resultados com a utilização do meio de cultura MS $1 / 2$ macro nutrientes suplementado com 40 g.L.-1 ${ }^{-1}$ de sacarose (SORACE et al., 2008).

Diferentemente do encontrado neste trabalho, para o híbrido Laeliocattleya schilleriana os resultados das variáveis biométricas analisadas demonstraram que o meio cultivo a base do fertilizante Hyponex ${ }^{\circledR}$ apresentou as maiores médias em comparação ao meio de cultivo a base de Kristalon Laranja ${ }^{\circledR}$ e ao meio MS $1 / 2$ macro nutrientes (CUNHA et al., 2011).

$\mathrm{O}$ efeito do $\mathrm{pH}$ nos meios nutritivos in vitro tem merecido atenção especial dos pesquisadores por sua atuação direta sobre a disponibilidade de nutrientes neles contidos (CHAPLA et al., 2009). Orquídeas são extremamente sensíveis a mudanças em seus níveis normais de $\mathrm{pH}$, apresentando, em alguns casos, intolerância a variações da ordem de 0,05, como no caso de representantes do gênero Encyclia, e tolerância em relação a maiores variações, até 1,5 , como em plantas do gênero Cattleya (PEDROSO-DE-MORAES, 2000).

$\mathrm{O} \mathrm{pH}$ de meios de cultivo se modifica à medida que diferentes íons são absorvidos e os produtos metabólicos são excretados para o meio, fato este principalmente causado pela absorção diferencial do amônio e do nitrato (MURDAD et al., 2006). 
Mesmo que o nível de pH 5,8 seja amplamente utilizado em biofábricas para a reprodução de variadas orquídeas, sabe-se que para o cultivo in vitro de Dendróbios, o melhor nível de pH para o desenvolvimento de espécies é 6,0 (PEDROSO-DEMORAES et al., 2010). Entretanto, informações sobre o desenvolvimento de plântulas do gênero em níveis de $\mathrm{pH}$ acima de 6,0 são praticamente inexistentes na literatura. Contudo, dentre as orquídeas de hábito epífito, os representantes deste gênero são os que mais apreciam meios nutritivos alcalinos. Tal sugestão é corroborada pelo fato de que neste trabalho os meios com $\mathrm{pH}$ ajustados para 6,3 assumiram os maiores valores para as variáveis fitotécnicas analisadas, diferentemente dos resultados obtidos para Baptistonia pubes cultivada em meio MS modificado e em meio a base de banana nanica acrescido de fertilizante NPK 20-20-20 Plant Prood $^{\circledR}$ (BAN), com pH ajustado para 6,2. Para esta espécie, tal ajuste de $\mathrm{pH}$ incorreu em valores intermediários para as variáveis analisadas (FERREIRA et al., 2010).

$\mathrm{O}$ ajuste de $\mathrm{pH}$ dos meios de cultivo para 5,8 obteve resultados intermediários para a maioria das variáveis fitotécnicas analisadas. Tal observação discorda de trabalhos recentes enfocando germinação e regeneração in vitro de orquídeas, para as quais os melhores resultados foram obtidos para meios de cultivo ajustados para este nível de pH (BESSON et al., 2010; GALE et al., 2010; SCHEIDT et al., 2010; SOARES et al., 2010; SOUTO et al., 2010; CHIU et al., 2011; KEEL et al., 2011; LIAO et al., 2011; ROY et al., 2011), ressaltando a sugestão, anteriormente citada, da preferência de representantes de Dendrobium a meios mais alcalinos (PEDROSO-DE-MORAES et al., 2010). Assim, devido a tal preferência, evidencia-se o porquê do nível de $\mathrm{pH}$ ajustado para 5,3 seja o que apresentou os piores resultados para a espécie estudada.

\section{CONCLUSÃO}

O meio de cultivo a base do fertilizante Kristalon Laranja ${ }^{\circledR}$ ajustado para o nível de $\mathrm{pH}$ de 6,3 mostrou-se o mais adequado para o cultivo in vitro de Dendrobium phalaenopsis "Madame Pompadour". 


\section{REFERÊNCIAS}

ARDITTI, J. Clonal propagation of orchids by means of tissue culture: a manual. In: ARDITTI, J. (Ed.). Orchid biology: reviews and perspectives. New York: Cornell University, 1997. v. 1, 468p.

ARDITTI, J.; ERNST, R. Physiology of germinating orchid seeds. In: ARDITTI, J. (Ed.). Orchid biology: reviews and perspectives III. New York: Cornell University Press. 1984. p. 177-222.

ARDITTI, J.; ERNEST, R. Micropropagation of orchids. New York: John Wiley \& Sons, 1992, 682p.

BESSON, J. C. F. et al. Fontes e concentrações de carboidratos no crescimento vegetativo e no enraizamento in vitro de Miltonia flavescens Lindl. Revista Brasileira de Biociências, v. 8, p. 9-13, 2010.

CAVAlINI, S. C. G.; GIANINI, P. F.; PEDROSO-DE-MORAES, C. Crescimento in vitro de Artemisia absinthium L. (Asteraceae) em meios de cultivo simplificados. Natureza on line, v. 12, p. 75-78, 2014.

CHAPLA, P. I. et al. pH, carvão ativado e agentes geleificantes do meio de cultura no crescimento in vitro de Miltonia flavescens Lindl. Plant Cell Culture \& Micropropagation, v. 5, p. 87-93, 2009.

CHIAPIM, C. et al. Crescimento in vitro em diferentes meios de cultura: avaliação do híbrido Brassavola perrinii Lindl. x Cattleya loddigesii Lindl. Orquidário, v. 26, p. 57-62, 2013.

CHIU, Y-T.; LIN, C-S.; CHANG, C. In vitro fruiting and seed production in Erycina pusilla (L.) N. H. Williams \& M. W. Chase. Propagation of Ornamental Plants, v. 11, p. 131-136, 2011.

CORDEIRO, G. M. et al. Desenvolvimento in vitro de Cattleya amethystoglossa Lindl. X (Cattleya dupreana X Laelia purpurata Lindl.). Revista Científica Eletrônica de Agronomia, v. 18, p. 22-28, 2011. 
CUNHA, T. et al. Desenvolvimento in vitro de Laeliocattleya scbilleriana Rolfe em meios de cultivo simplificados. Scientia Plena, v. 7, p. 1-5, 2011.

DAVIDSON, B. Dendrobium breeding trends. American Orchid Society Bulletin, v. 63, p. 638-645, 1994.

DEZAN, L. F. et al. Crescimento in vitro de Schomburgkia gloriosa Lindl. em meio de cultivo simplificados. Idesia (Arica), v. 30, p. 53-58, 2012.

FERREIRA, A. W. C. et al. Propagação in vitro de Baptistonia pubes (Lindl.) Chiron \& V. P. Castro (Oncidium pubes Lindl.) (Orchidaceae). Acta Botanica Brasilica, v. 24, p. 636-639, 2010.

GALE, S. W. et al. Constraints on establishment in an endangered terrestrial orchid: a comparative study of in vitro and in situ seed germinability and seedling development in Nervilia nipponica. Botanical Journal of the Linnean Society, v. 163, p. 166-180, 2010.

KAMEMOTO, H.; AMORE, T. D.; KUHNLE, A. R. Breeding Dendrobium: orchids in Hawaii. Canadá: University of Hawai Press, 1999, 166 p.

KÄMPF, A. N. Produção comercial de plantas ornamentais. Porto Alegre: Ed. Guaíba, 2000, 254 p.

KEEL, B. G.; ZETTLER, L. W.; KAPLIN, B. A. Seed Germination of Habenaria repens (Orchidaceae) in situ Beyond its Range, and its Potential for Assisted Migration Imposed by Climate Change. Castanea, v. 76, p. 43-54, 2011.

KERBAUY, G. B. Biofábrica de orquídeas. In: GERALD, L. T. S. (Ed.). Biofábrica produção industrial de plantas in vitro. Araras: Ed. da UFSCar, 1995. p. 22-24.

KNUDSON, L. A new nutrient solution for germination of orchid seed. American Orchid Society Bulletin, v. 15, p. 214-217, 1946.

LIAO, Y-J. et al. In vitro shoot induction and plant regeneration from flower buds in Paphiopedilum orchids. In Vitro Celular \& Developmental Biolog y - Plant, v. 47, p. 702-709, 2011. 
LORENZI, H.; SOUZA, H. M. Plantas ornamentais no Brasil: arbustivas, herbáceas e trepadeiras. Nova Odessa: Instituto Plantarum, 1999. 1120 p.

MASSARO, R. et al. Avaliação do desenvolvimento in vitro de Epidendrum secundum Jacq. em meios de cultivo simplificados. Rama: Revista em Agronegócio e Meio Ambiente, v. 5, p. 337-351, 2012.

MURASHIGE, T.; SKOOG, F. A revised medium for rapid growth and bio-assays with tobacco tissue cultures. Physiologia Plantarum, v. 15, p. 473-497, 1962.

MURDAD, R. et al. High multiplication of Phalaenopsis gigantea using trimmed bases protocorms technique. Scientia Horticulturae, v. 111, p. 73-79, 2006.

PEDROSO-DE-MORAES, C. Cultivo de Orquídeas. Araras: Biblioteca Duse Rüegger Ometto. 2000. 145 p.

PEDROSO-DE-MORAES, C. et al. As orquídeas e o mercado. Boletim das Associações Orquidófilas do Brasil (CAOB), v. 66/67, p. 38-41, 2007a.

PEDROSO-DE-MORAES, C. et al. Anatomia radicular de Dendrobium Stardust. Boletim das Associações Orquidófilas do Brasil (CAOB), v. 68, p. 91-96, 2007b.

PEDROSO-DE-MORAES, C. et al. Desenvolvimento in vitro de Cattleya loddigesii Lindley (Orchidaceae) utilizando fertilizantes comerciais. Revista Brasileira de Biociências, v. 7, p. 67-69, 2009a.

PEDROSO-DE-MORAES, C. et al. Desenvolvimento in vitro de Cattleya tigrina A. Richard (Orchidaceae) utilizando fertilizantes comerciais. Ensaios e Ciência, v. 13, p. 57-65, 2009b.

PEDROSO-DE-MORAES, C. et al. Desenvolvimento in vitro de Dendrobium nobile Lind. (Orchidaceae) em recipientes de diferentes volumes. Revista Brasileira de Biociências, v. 8, p. 225-228, 2010.

PEDROSO-DE-MORAES, C. et al. AIA no estímulo de brotos laterais em estacas de Dendrobium nobile Lindley (Orchidaceae). Ensaios e Ciência, v. 15, p. 111, 2011. 
PIERIK, R. L. M. In vitro culture of higher plants. Dordrecht. M. Nyjhoff. 1987. $231 \mathrm{p}$.

PIMENTA, R. Dendrobium nobile. Disponível em: < http://www.fbpro.com.br/ index.php.> Acesso em: 26 jun. 2006.

PRAKASH, L. C. L.; GOH, C. J. In vitro propagation of commercial orchids: an assessment of current methodologies and development of a novel approach thin section culture. Jornal of the Orchid Society of India, v. 10, p. 31-41, 1996.

REDDY, P. V.; NANJAN, K.; SHANMUGAVELU, K. G. In vitro studies in tropical orchids: seed germination and seedling growth. Coimbatori, v. 6, p. 75-78, 1992.

REGO-OLIVEIRA, L. V.; FARIA, R. T. In vitro propagation of Brazilian orchids using traditional culture media and commercial fertilizers formulations. Acta Scientiarum Agronomy, v. 27, p. 1-5, 2005.

RODRÍGUEZ, L. et al. Producción y recuperación de orquídeas silvestres cubanas. v. 1, p. 4-9, 2005. Disponível em: <http://www.secretariadeambiente gov. co/sda/libreria/pdf/ecosistemas/restauracion/1_ar26.pdf> Acesso em: 22 dez. 2011.

ROSA, M. D.; LANERI, U. Modification of nutrient solutions for germination and growth in vitro of some cultivated orchids and the vegetative propagation of Cymbidium cultivars. American Orchid Society Bulletin, v. 46, p. 813-820, 1977.

ROY, A. R. et al. Asymbiotic seed germination, mass propagation and seedling development of Vanda coerulea Griff ex.Lindl. (Blue Vanda): An in vitro protocol for an endangered orchid. Scientia Horticulturae, v. 128, p. 325-331, 2011.

SANTANA, D. G.; RANAL, M. A. Análise da Germinação: um enfoque estatístico. Brasília: Universidade de Brasília, 2004, 229 p.

SCHEIDT, G. N. et al. Multiplicação in vitro de Oncidium leucochilum (Orchidaceae) em diferentes sistemas de cultivo. Biociências, v. 17, p. 82-85, 2010. 
SCHELPE, S.; STEWART, J.Dendrobium: an introduction to the species in cultivation. Stour Provost: Orchid Sundries, 1990, 114 p.

SOARES, J. D. R. et al. Estiolamento e luz artificial no cultivo in vitro de orquídeas nativa e híbrida. Ciência Rural, v. 40, p. 1941-1947, 2010.

SORACE, M. et al. Crescimento in vitro de Oncidium baueri (Orchidaceae) em diferentes concentrações de macronutrientes e sacarose. Semina: Ciências Agrárias, v. 29, p. 775-782, 2008.

SOUTO, J. S. et al. Efeitos do ácido naftalenoacético no desenvolvimento in vitro de Cattleya bicolor Lindl. (Orchidaceae). Revista Brasileira de Biociências, v. 8, p. 179-185, 2010.

STANCATO, G. C.; FARIA, R. T. In vitro growth and mineral nutrition of the lithophytic orchid Laelia cinnabarina Batem (Orchidaceae): effects of macro and microelements. Lindleyana, v. 11, n. 1, p. 41-43, 1996.

STANCATO, G. C.; BEMELmanS, P. F.; VEGRO, C. L. R. Produção de mudas de orquídeas a partir de sementes in vitro e sua viabilidade econômica: estudo de caso. Revista Brasileira de Horticultura Ornamental, v. 7, p. 25-33, 2001.

TRUJILLO, G.; HERNÁNDEZ, Y. Bacterial spot in orchid. Fitopatologia Venezoelana, v. 12, p. $4-8,1999$.

VACIN, E. F.; WENT, F. W. Some pH changes in nutrient solutions. Botanical Gazette, v. 110, p. $604-613,1949$.

Recebido em: 21 de maio de 2015 Aceito em: 23 de janeiro de 2016 